B. Jones: The Open University is largely funded by central government, with much smaller contributions from other bodies, including foundations and industry. The students on degree courses pay only a small fraction of the true costs.

Roughly speaking, it costs about $\$ 4,000$ to obtain a full honors degree, and this will be spread over, typically, six years.

\title{
A SELF-PACED MASTERY-ORIENTED INTRODUCTORY ASTRONOMY COURSE
}

\author{
John L. Safko
}

Department of Physics and Astronomy, University of South Carolina, Columbia, South Carolina 29208, U.S.A.

I will be describing a self-paced mastery-oriented introductory astronomy course that has been offered at the University of South Carolina since 1972. This course is a three-semester sequence with total enrollments of 800-1000 students per term. Most of the enrollment is for the first semester of the sequence. Although these particular courses are designed for non-science majors, I believe that the methods developed in these courses can be applied to courses for astronomy majors. These methods could provide a solution to the problems of teaching classes and, at the same time, traveling for research and meetings.

A mastery-oriented course involves developing a list of learning objectives that are described in terms of performance of given tasks. That is, words such as understand and appreciate should not be used. Performance objectives involve words such as recognize, calculate, measure, and describe. Any set of learning objectives must be tied to a set or readings, a textbook, and/or supplementary notes. These items are chosen or written by the instructor(s) to provide the background necessary for the students to master the objectives.

At the University of South Carolina, our learning objectives were developed by examining the test questions that had been collected from 5 years of a regular lecture course. This allowed us to determine what performance we were expecting from the students, rather than guessing what the learning objectives should be. In a few cases it became obvious that additional objectives and/or additional questions were needed. In some cases it was clear that questions should be eliminated. Item analysis and student questions told us what notes in addition to the text were needed. We combined the objectives, the notes, and the laboratory materials that we use into a single volume.

A regular text publisher would want modifications in order to sell sufficient copies to justify publication. Rather than remove all references to particular procedures at our institution, we chose to go to a publisher who prints and ware- 
houses sufficient copies for two-year intervals. A sample of the volume, published by Kendall/Hunt Publishing Company, was on display at this meeting.

As an aside, this method of publishing can provide texts for small enrollment courses such as graduate astronomy courses. With today's microcomputers and word processing programs, an author can prepare camera-ready copy for printing that reduces the cost of small press runs to a reasonable level. In those countries where regular publishers are not interested in publishing astronomy textbooks, you could prepare a camera-ready copy and take it to a local printer, and arrange for the students to buy them. If no other option is available, you can even pay for the press run and hope to recover your investment from sales. All questions of ethics can be resolved by selling at a price that will only recover costs and a modest payment for the preparation time. Thus, I believe, students in any country can have texts in their native tongue.

A self-paced course allows students to progress at their own rate, subject to the scheduled completion time of the course. We have an area that is open about 40 hours per week. During the open time, students can come at times of their own choice to use our study materials and to show mastery of portions of the material. A majority of the students spread their work out over the semester, but, as might be expected, some put the course off until the last days of the term. These are the same students who wait until the night before a scheduled exam to study.

We have an audio-visual room with computer programs, video tapes, and slide material covering selected material from the course. Many of the video tapes and some of the computer programs were made at the university specifically for this course. All students are encouraged to try the material in the audio-visual room. Those students who are having difficulty with particular concepts are directed to the appropriate tape or program. The video tapes thus take the place of lectures with the advantage of being available and repeatable whenever desired by the student rather than only at fixed times.

Most of our evaluation is carried out with multiple choice questions, although some of the material also has brief paragraphs expected. Answer keys are provided for the staff to use. This evaluation process allows us to use staff who may not be able to answer all the questions themselves. The mastery evaluations are computergenerated from a large field of questions that are subdivided into the learning objectives. For any given subject a large number of different evaluations are available; hence, those students who need to repeat receive a completely different test on the next try. We require 13 correct responses out of 15 questions for credit. If mastery is not achieved, immediate feedback is provided by reference to the learning objectives the missed questions were testing. If that is not sufficient and if the staff in the testing center is not able to help, the student is referred to one of the senior staff or to me.

Most of the staff and laboratory instructors are recruited from students who have successfully completed the course. Many of these are not science majors. 
This procedure has the advantage of having a staff who have seen the course from the students' viewpoint. We have also found that many non-science students are, unreasonably, intimidated by science students. Thus a non-science student staff can often provide aid and a friendly ear where a physics or astronomy major could not (note, I said "could not," not "would not").

Although the course I have been describing was designed for non-science majors, I present it as a possible model for undergraduate and graduate major astronomy courses. By freeing ourselves from a fixed schedule of lectures, we allow greater flexibility in travel and observation. There are also educational advantages in forcing the student to take more responsibility for his or her own learning process. Texts, articles, and prepared notes can provide most of the aids that a student needs. Individual consultation and student study groups can fill in any remaining gaps. Feedback from the students will show you where the notes need further detail.

Our self-paced astronomy has a large enrollment, so we can offer the students a large number of possible testing and audiovisual hours and still be economical. Smaller enrollment courses would, probably of necessity, have fewer hours available to the student. This handicap can be overcome, in part, by computer testing and the minimal need to proctor students in advanced courses. We have also found that several courses can be offered with the same testing and audio-visual center.

There are several caveats you must consider before embarking on this method of teaching:

1. Don't consider a self-paced course to save yourself time. You will spend a larger amount of time in preparation, organization, and dealing with individual students than you would in a normal lecture course. This time spent, however, will be more productive since much of it will be spent with individual students.

2. Self-paced, mastery-oriented courses require careful preparation and more attention to detail than you would spend with a normal lecture course.

3. If several faculty share a single course, one person must be clearly in charge and responsible for all exceptions to the rules.

4. If commercial texts do not meet your needs, you will have to write extensive notes, which will take additional time.

5. You must be philosophical about what students do to themselves. It is their responsibility to study and read the material, not yours.

I hope this brief introduction can give you an idea of the nature of self-paced, mastery-oriented instruction and that it may inspire a few of you to experiment with this method.

\section{Discussion}

P.P. Saxena: This type of teaching is only useful for those institutions where there is a scarcity of astronomy teachers and/or where the number of students is very large. 
J.L. Safko: The particular course that I described is offered at such an institution (scarcity of astronomy teachers and a large number of students); however, this is not the only situation where the method would be useful. Observation schedules and shifts in telescope scheduling may pull astronomy faculty from their home institution at odd times in the year causing a disruption of normal classes. Then another faculty or graduate student must cover those lectures in addition to their normal classes. Proper scheduling of self-paced duties can eliminate this problem.

The efficiencies of size can be gained by combining the evaluation process for several courses into one administrative structure, open hours, and location. This would allow a few classes of 5 or 6 students to be incorporated with several introductory classes with minimal or no extra staffing over the introductory class needs.

The main difficulty with self-paced courses involving several instructors is reaching an agreement on the wording of the learning objectives for the course. This problem must be resolved to everyone's satisfaction for the method to be successful.

A. Fraknoi: I may be the Neanderthal of astronomy teaching, but I have one concern about the very interesting program you have described. I remember vividly that during my college education, some of the most exciting and valuable experiences involved watching and hearing a brillant scholar/teacher interact with others students, respond to questions in class, digress about his own work or recent discoveries, and share his or her personal love and excitement about the field. Is there a role for an inspiring live lecturer in a course such as the one you described?

J.L. Safko: Many students do not agree. They choose astronomy because they won't have to go to lectures 2 or 3 times per week. I do offer special opportunties for credit for attending lectures, such as those given by visiting astronomers, special lectures at the local astronomy club, etc. Educational psychologists say that the only factor that correlates with a student's grade and learning is how much work he/she puts into the course. 